\title{
Adult attachment and parenting stress among parents of toddlers
}

\author{
Maria Nygren, John Carstensen, Johnny Ludvigsson and Anneli Sepa
}

\section{Linköping University Post Print}

N.B.: When citing this work, cite the original article.

This is an electronic version of an article published in:

Maria Nygren, John Carstensen, Johnny Ludvigsson and Anneli Sepa, Adult attachment and parenting stress among parents of toddlers, 2012, Journal of Reproductive and Infant Psychology, (30), 3, 289-302.

Journal of Reproductive and Infant Psychology is available online at informaworld ${ }^{\mathrm{TM}}$ : http://dx.doi.org/10.1080/02646838.2012.717264

Copyright: Taylor \& Francis (Routledge): STM, Behavioural Science and Public Health Titles / Taylor \& Francis (Routledge)

http://www.routledge.com/

Postprint available at: Linköping University Electronic Press

http://urn.kb.se/resolve?urn=urn:nbn:se:liu:diva-84912 


\title{
Adult Attachment and Parenting Stress among Parents of Toddlers
}

\author{
Maria Nygren ${ }^{1}$, MS, PhD stud, John Carstensen ${ }^{2}, \mathrm{PhD}$, Prof, Johnny Ludvigsson ${ }^{1}, \mathrm{PhD}$, \\ MD, Prof, \& Anneli Sepa Frostell ${ }^{1,3}, \mathrm{PhD}$, Senior Lecturer \\ ${ }^{1}$ Div. of Pediatrics and Diabetes Research Centre, Dept. of Clinical and Experimental \\ Medicine, Faculty of Health Sciences, Linköping University, Linköping, Sweden \\ ${ }^{2}$ Div. of Health and Society, Dept. of Medical and Health Sciences, Faculty of Arts and \\ Sciences, Linköping University, Linköping, Sweden
}

${ }^{3}$ Div. of Cognition, Development and Disability, Dept. of Behavioral Sciences, Faculty of Arts and Sciences, Linköping University, Linköping, Sweden

Running title: Adult Attachment and Parenting Stress

Key words: Adult attachment, attachment styles, parenting stress, parenting, family relations

\section{Word count:}

Abstract: 196

Manuscript: 3535

\section{Corresponding author:}

Maria Nygren

Div. of Pediatrics

Dept. of Clinical and Experimental Medicine

Faculty of Health Sciences

Linköping University

SE-581 85 Linköping

Sweden

E-mail: Maria.Nygren@liu.se

Phone: +46-10-103 1312

E-mail: Maria.Nygren@liu.se

Phone: +46-10-103 1312

\section{Acknowledgement:}

The authors thank the parents for their participation in ABIS. We also thank the staff and nurses at the 250 well-baby clinics and the ABIS research nurses for their help in logistics and data collection. We also thank prof. Ann Frodi for valuable expertise and constructive ideas. The current work was generously supported by the Swedish Research council (K2005-72X-11242-11A, K2008-69X-20826-01-4) and the Swedish Child Diabetes Association (Barndiabetesfonden). ABIS has also been generously supported by JDRF Wallenberg Foundation (K 98-99D-12813-01A), Medical Research Council of Southeast Sweden (FORSS), and the Swedish Council for Working Life and Social Research (FAS2004-1775). None of the authors have any conflict of interests to disclose. 



\begin{abstract}
Objective: The aim was to revise the dimensionality of the Relationship Scales Questionnaire (RSQ) assessing adult attachment and relate it to parenting stress within a large sample of parents of toddlers. Methods: As part of a longitudinal population-based study, 8122 parents (97\% mothers) completed the 18 item version of RSQ and the Swedish Parenthood Stress Questionnaire (SPSQ) when their child was 2-3 years of age. Results: Exploratory factor analyses gave three uncorrelated RSQ-factors named (1) Importance of Independence, (2) Relationship-related Anxiety, and (3) Discomfort with Closeness, with Cronbach's $\alpha \geq 0.65$. In a linear regression Parenting Stress was most closely related to Relationship-related Anxiety $(b=0.20, t=39.0)$, weaker associations were found with the attachment dimensions capturing avoidance: Importance of Independence $(b=0.07$, $t=13.40)$ and Discomfort with Closeness $(b=0.07, t=12.04)$. The SPSQ-subscales Incompetence $\left(R^{2}=17 \%\right)$ and Social Isolation $\left(R^{2}=22 \%\right)$ showed stronger association with adult attachment than the remaining three. Conclusion: The agreement with previous findings in other study populations indicates that substantial and meaningful dimensions of attachment have been captured. Attachment anxiety and discomfort with closeness seem to have an important relationship with the perception of parenting stress, especially concerning feelings of incompetence and social isolation.
\end{abstract}




\section{Introduction}

The family plays an important role in a child's experience of stressful events and in the potential coping strategies used. The quality of the relationship between children and their caregivers is important for children's development, emotional regulation, and for learning how to cope with stress. Psychological stress in the family has been linked to a biological stress-reaction (activation of the HPA-axis/increased cortisol) within the child (Essex et al., 2002; Koch, Ludvigsson, \& Sepa, 2010; Turner-Cobb, 2005) and negative effects on child health such as obesity (Koch, Sepa, \& Ludvigsson, 2008) and diabetesrelated autoimmunity (Sepa et al., 2005).

The theory of adult attachment (e.g. Collins \& Read, 1990; Griffin \& Bartholomew, 1994a; Hazan \& Shaver, 1987) has been used as a framework to understand romantic relationships between adults and how the current relationship is influenced by experiences of earlier relationships, mainly the primary one with a caregiver. The way the parents act in intimate relationships might affect the level of stress in the family, for example by affecting the parent's perception of and coping with stressful events, since attachment style both regulates the ability to cope with stress and the willingness to seek, as well as the possibility to benefit from, social support (Collins \& Feeney, 2000; Fraley \& Shaver, 1998; Moreira et al., 2003; Simpson, Rholes, \& Nelligan, 1992; Simpson et al., 2002). Therefore, it is reasonable to assume that attachment style may also affect parenting stress.

In large epidemiological studies, we are obliged to use self-report measures and it is necessary to continue the development of existing instruments, such as those assessing adult attachment style. The current study aims to revise the dimensionality of a self-report questionnaire for adult attachment and relate it to a validated instrument for parenting stress within a population of parents of toddlers.

Different self-report questionnaires measuring adult attachment are available (e.g. 
Collins \& Read, 1990; Fraley, Waller, \& Brennan, 2000; Simpson, Rholes, \& Nelligan 1992; for a review see Ravitz et al., 2010). The Relationship Scale Questionnaire (RSQ; Griffin \& Bartholomew, 1994b) was used in the current study. To our knowledge, RSQ has only been validated on samples consisting of students (Bäckström \& Holmes, 2001; Griffin \& Bartholomew, 1994b; Roisman et al., 2007), couples where a majority were noncohabiting young adults probably without children (Stein et al., 2002), or older adults without small children (Kurdek, 2002). Originally, the RSQ was designed to capture the two attachment-related dimensions 'Model of Other' and 'Model of Self'. However, since 2000, the year our data were collected, less satisfactory goodness-of-fit values have been found for that model (Kurdek, 2002; Roisman et al., 2007). The current study aims to investigate the fit of the new RSQ-factors within a population of parents of toddlers.

In this study parenting stress is understood to occur as the result of a perceived discrepancy between the specific demands associated with being a parent and the parent's personal resources (Östberg, Hagekull, \& Hagelin, 2007). Two studies have investigated attachment style and the relationship with parenting stress. The first found more stress in several domains of parenting among parents with fearful attachment styles (Vasquez, Durik, \& Hyde, 2002), and the second found more parenting stress among avoidantly attached parents after birth of their first child (Rholes, Simpson, \& Friedman, 2006). Psychological factors such as general anxiety and low self-esteem have also been found to predict parenting stress in mothers of 2 to 3 year old children (Saisto et al., 2008). Other studies have also reported that individuals with a more anxious attachment style both experience and report more emotional distress (Collins, 1996; Fraley \& Shaver, 1998). Based on the previous literature we predicted positive associations between attachment avoidance as well as anxiety and parenting stress. 


\section{Method}

\section{Participants and procedure}

The current study is a part of a population based longitudinal cohort study aiming to study child health. Of all families expecting a child in the region between October 1997 and October 1999, 79\% (17 055) chose to participate. Questionnaire data were collected at six time points (at birth and at 1, 2-3, 5-6, 8 and 10-12 years of age); the current study uses questionnaire data collected when the children were 2-3 years old; 8122 completed the whole RSQ of whom $97 \%(n=7852)$ were mothers and 3\% $(n=270)$ fathers, see Table 1.

A total of 16070 parents completed the questionnaire at birth and $8122(51 \%)$ at 2-3 years, giving a drop out of $49 \%$. The attrition analysis indicated that parents not born in Sweden, single parents, or parents with more children were somewhat less likely to participate, whereas older parents and parents with higher education were somewhat more likely to participate, see Table 1.

Data were collected in connection with a regular check up at the well baby clinic, utilized by around $99 \%$ of all parents in the country. There were no instructions indicating which parent should answer the questionnaire and no reminders were used.

\section{Measures}

Adult attachment styles were assessed with a translation of the Relationship Scale Questionnaire (RSQ; Griffin \& Bartholomew, 1994b) consisting of 18 items on 7-point Likert-scales ranging from not at all like me to very much like me. In the original scale construction, item 6 was used in two subscales (Griffin \& Bartholomew, 1994b). In our translation of item 2 ("It is very important to me to feel independent") and item 19 ("It is very important to me to feel self-sufficient") the same Swedish word was unfortunately used for "independent" and "self-sufficient", giving two identically worded items. 
Consequently, item 19 was excluded giving 16 unique items for the analyses.

Table 1:

Descriptive of demographic variables and dropout analysis with multiple logistic regression.

Variable

Age (Mean $(S D))$

Born outside Sweden

Education - compulsory 9 years

Education - secondary school $10-12$ years

Education - university level at least 1 year

Single parent

Number of children (Median)

$n$

${ }^{\text {*1 }}$ Multiple logistic regression predicting completion of 2 year follow up or not by demographic factors at birth

${ }^{\star 2}$ All $O R<0.001$ except education university level $p=0.002$

${ }^{*_{3}}$ In the logistic regression/dropout analysis $0=$ both parents born in Sweden $1=$ one or both parents born outside Sweden

*4 Missing cases $n=737$

Parenting stress was assessed with the Swedish Parenting Stress Questionnaire (SPSQ), which is a translation and reconstruction of the Parenting Stress Index (Abidin, 1990) validated for Swedish conditions (Östberg, Hagekull, \& Wettergren, 1997 ). The SPSQ consists of 34 items across five subscales: Incompetence (11 items), Role Restriction (7 items), Social Isolation (7 items), Spouse Relationship Problems (5 items), and Health Problems (4 items). Together these five subscales form an overall parenting stress score. SPSQ has shown good construct validity as it relates to common stressors and is theoretically associated factors such as social support and child fussyness-difficultness (Östberg, Hagekull, \& Wettergren, 1997; Östberg \& Hagekull, 2000; Östberg, Hagekull, \& Hagelin, 2007). The SPSQ has also shown good stability over time (test-retest correlation 
over 30 days: $r=0.89$, and $0.86 \leq r \leq 0.79$ for each subscale) and acceptable homogenity (Cronbach's alpha $(\alpha)=0.89$, and $\alpha>0.68$ for each subscale; Östberg, Hagekull, \& Wettergren, 1997). The statistical reliability for SPSQ in our sample was good: Complete scale $\alpha=.89$, Incompetence $\alpha=.82$, Role Restriction $\alpha=.80$, Spouse Relationship Problems $\alpha=.77$, Social Isolation $\alpha=.71$, and Health Problems $\alpha=.60$. In the current study, each item was assessed on a 6-point Likert-scale ranging from strongly disagree to strongly agree, a stress score for each individual was calculated as the mean of the items included in each subscale (after reversing reversed items). In order to make it possible for single parents to participate, the inclusion criterion was set to 29 (of 34) questions answered on the complete scale (i.e. allowing internal dropout concerning the spouse relationship subscale).

Demographic variables used were: parental gender (mother/father); parental age when the target child was born; level of education in three categories (compulsory school 9 years/secondary school 10-12 years/university for at least 1 year); parental origin (born in Sweden/born abroad); marital status (living with partner/being a single parent); and number of children $(1,2,3,4,5$ or more) which was approximated by the number of siblings of the target child.

\section{Statistics}

Revision of the $R S Q$

Exploratory factor analysis was used to revise RSQ. To avoid multicolinearity in later analyses varimax rotation was used. Items were excluded stepwise until each item had one strong loading (> |0.50|; Hair et al., 1998) on one factor.

Confirmatory factor analysis was used to compare the goodness-of-fit values between our and Griffin and Bartholomew's original factor structure. A root mean square error of 
approximation $(R M S E A)$ of $<0.05$ was considered a good fit and $0.05-0.08$ an acceptable fit (Hair et al., 1998). A comparative fit index (CFI) between $0.90-0.95$ is recommended (McDonald \& Ho, 2002) whereas a $C F I<0.80$ should be seriously considered (Blunch, 2008). The intention of the current study was to compare two models derived from exploratory factor analysis rather than increase the fit of a structural equation model. Therefore, a $C F I>0.80$ could be accepted especially in combination with a RMSEA < 0.08 .

\section{Associations with parenting stress}

Associations were examined by a hierarchical linear regression where each SPSQ scale was set as response variable. Demographic variables were used to adjust the level of parenting stress before investigating its associations to attachment style. Gender-effect for the fathers was modelled as interaction-variables with each RSQ-style. Predictor variables were included as steps in the following order: (1) demographic variables, (2) RSQ dimensions, (3) gender-interactions, and (4) interaction-terms with the remaining demographic variables. A $p$-value of $<0.05$ was considered statistically significant for step one to three. Due to the large number of interaction-terms in step four (6 demographic variables $\times 3$ RSQ styles $=18$ interaction variables) simultaneous tests of $\beta_{j}$ with Bonferroni correction - family level of significance at 0.05 (every $\beta_{j}$ was tested on $\alpha=$ $0.05 / 18=0.0028)-$ was used to lower the risk of chance findings. For every SPSQ outcome (Complete scale and five subscales) a regression model was fitted; hence, in total, six models were tested. The assumption of linearity was tested separately by adding quadratic terms of the RSQ as step 3 after adding demographic variables and the linear terms of the RSQ dimensions. Statistical analyses were performed in PASW Statistics 18 Release 18.0.0 and in Amos 18.0.0. 


\section{Results}

\section{Reconstruction of RSQ}

The initial exploratory factor analyses gave rise to four factors for mothers and four for fathers with eigenvalues greater than one (latent root criterion). These were adjusted into three-factor solutions according to the scree-plots. Three items were excluded for mothers (item 5, 15, and 12) and two for fathers (item 15, 12). The final three-factor solutions are presented in Table 2. The new attachment styles were named (1) Importance of Independence, (2) Relationship-related Anxiety, and (3) Discomfort with Closeness. Each dimensions had Cronbach's $\alpha \geq 0.65$, indicating acceptable reliability (Hair et al., 1998). Intercorrelations between the styles were close to zero due to Varimax rotation. Oblim rotation was also tested but hardly made any difference (data not shown). The revised 14-item instrument was called the Swedish Relationship Scales Questionnaire (SwRSQ-14).

The confirmatory factor analysis of the original model (Griffin \& Bartholomew, 1994b), with two uncorrelated factors: (1) Model of Other and (2) Model of Self, gave CFI $=0.62$ and $R M S E A=0.081$, indicated that the original model did not have an acceptable goodness-of-fit in our sample. The 3-factor model developed in the current study yielded a $C F I=0.82$ and a $R M S E A=0.060$, indicating a valuable improvement, even if not quite an excellent fit. The three new dimensions were judged more suitable for the assessment of attachment styles in a Swedish sample of parents than were the original two. However, had we chosen a two-factor model, the exploratory factor analysis would have merged Importance of Independence and Discomfort with Closeness into one factor (data not shown). Analyses of the association between the original two factors and our three new factors yielded strong correlations between Model of Self and Relationship-related Anxiety 
Table 2

Exploratory factor analyses of RSQ: Factor loadings ${ }^{\star 1}$, eigenvalues, proportion of variance, factor names and Cronbach's alpha.

\begin{tabular}{|c|c|c|c|c|c|c|c|}
\hline \multirow{2}{*}{$\begin{array}{l}\text { Item no. and } \\
\text { classification }{ }^{\star 2}\end{array}$} & \multirow[b]{2}{*}{ Question } & \multicolumn{3}{|c|}{ Mothers $(n=7852)$} & \multicolumn{3}{|c|}{ Fathers $(n=270)$} \\
\hline & & Factor 1 & Factor 2 & Factor 3 & Factor 1 & Factor 2 & Factor 3 \\
\hline 1, Fear & I find it difficult to depend on other people. & 0,69 & & & 0,58 & & \\
\hline 2 (19), Dis ${ }^{\star 3}$ & It is very important to me to feel independent (self-sufficient). & 0,68 & & & 0,71 & & \\
\hline 22, Dis & I prefer not to have other people depend on me. & 0,50 & & & 0,64 & & \\
\hline 26, Dis & I prefer not to depend on others. & 0,77 & & & 0,80 & & \\
\hline $10, \mathrm{Sec}$ & I am comfortable depending on other people. & $-0,69$ & & & $-0,65$ & 0,34 & \\
\hline \multirow[t]{2}{*}{ 5, Fear } & I worry that I will be hurt if I allow myself to become too close & & & & & & \\
\hline & to others. & \multicolumn{3}{|c|}{ excluded from the analysis ${ }^{\star 5}$} & & 0,61 & \\
\hline 16, Pre & I worry that others don't value me as much as I value them. & \multicolumn{3}{|c|}{0,78} & & 0,75 & \\
\hline 25, Pre & I find that others are reluctant to get as close as I would like. & \multicolumn{3}{|c|}{0,70} & & 0,66 & \\
\hline $28, \mathrm{Sec}$ & I worry about having others not accept me. (reversed) & \multicolumn{3}{|c|}{$-0,78$} & & $-0,74$ & \\
\hline 9, Dis & I worry about being alone. (reversed) & \multicolumn{3}{|c|}{$-0,61$} & & $-0,54$ & \\
\hline 6, Dis/Pre- $R^{\star^{4}}$ & I am comfortable without close emotional relationships. & \multicolumn{3}{|r|}{0,71} & & & 0,69 \\
\hline 24, Fear & I am uncomfortable being close to others. & \multicolumn{3}{|r|}{0,66} & & & 0,64 \\
\hline $3, \mathrm{Sec}$ & I find it easy to get emotionally close to others. & \multicolumn{3}{|r|}{$-0,69$} & & & $-0,67$ \\
\hline 8, Pre & I want to be completely emotionally intimate with others. & \multicolumn{3}{|r|}{$-0,71$} & & & $-0,74$ \\
\hline $15, \mathrm{Sec}$ & I am comfortable having other people depend on me. & \multicolumn{3}{|c|}{ excluded from the analysis ${ }^{* 5}$} & \multicolumn{3}{|c|}{ excluded from the analysis ${ }^{* 5}$} \\
\hline
\end{tabular}




\section{2, Fear I find it difficult to trust others completely.}

Eigenvalue before rotation

Proportion of the total variance after varimax rotation

Factor name

Cronbach's $\alpha$

${ }^{* 1}$ Loadings $<|0.30|$ has been counts as zero and are not presented

*2 Original RSQ item number and attachment classification (Griffin \& Bartholomew, 1994). Fear $=$ Fearful, Dis $=$ Dismissing, Sec $=$ Secure, Pre $=$ Preoccupied

*3 Item 2 and 19 had the same wording in the Swedish translation.

${ }^{*}$ Item used twice, as dissmissing and preoccupid ( $\mathrm{R}=$ reversed coding), in the original RSQ scale construction (Griffin \& Bartholomew, 1994).

${ }^{* 5}$ Item excluded from final factor solution due to no strong loadings. excluded from the analysis ${ }^{\star} 5$

\begin{tabular}{cccccc}
2,8 & 2,2 & 1,7 & 2,9 & 2,4 & 1,6 \\
$18,0 \%$ & $17,6 \%$ & $16,2 \%$ & $17,6 \%$ & $17,5 \%$ & $14,7 \%$ \\
\hline Important with & Relationship & Discomfort & Important with & Relationship & Discomfort \\
independence & related anxiety & with closeness & independence & related anxiety & with closeness \\
0,70 & 0,70 & 0,67 & 0,71 & 0,70 & 0,65
\end{tabular}


$(r=0.75, p<0.001)$, and between Model of Other and Importance of Independence $(r=$ $0.75, p<0.001)$ as well as between Model of Other and Discomfort with Closeness $(r=$ $0.66, p<0.001)$. The remaining three correlations were weak $(r<0.19)$.

\section{Associations with parenting stress}

The three factors measuring attachment styles together (step 2) showed significant associations with overall Parenting Stress as well as with each subscale after controlling for demographic variables (step 1), see Table 3. Cronbach's $\alpha$ was not substantially lower for the SPSQ-subscales with lower $R^{2}$ (except for Health Problems), indicating that the findings not were due different amounts of measurement error in the different SPSQsubscales. No significant gender-effect (step 3) was found, see Table 3.

Differences between the subgroups were explored by interaction-effects (step 4). Significant effects were found for the group of parents born outside Sweden, and the subgroup of single parents, see Table 3. The quadratic terms of the three SwRSQ-14 subscales increased the $R^{2}$ less than $1 \%$ for all SPSQ-scales (data not shown), as they added no major improvement linearity was assumed. 
Table 3

Hierarcical ${ }^{* 1}$ multiple linear regression predicting SPSQ complete scale and subscales.

\begin{tabular}{|c|c|c|c|c|c|c|c|c|c|}
\hline & \multicolumn{3}{|c|}{ Complete scale $(n=7728)$} & \multicolumn{3}{|c|}{ Incompetence $(n=7615)$} & \multicolumn{3}{|c|}{ Role Restriction $(\mathrm{n}=7532)$} \\
\hline & $\Delta R^{2}$ & $F$ & $p$ & $\Delta R^{2}$ & $F$ & $p$ & $\Delta R^{2}$ & $F$ & $p$ \\
\hline Parental gender and Demographic variables & $2,4 \%$ & 27,00 & 0,000 & $0,3 \%$ & 3,46 & 0,001 & $2,1 \%$ & 22,93 & 0,000 \\
\hline RSQ dimensions & $21,4 \%$ & 724,56 & 0,000 & $16,9 \%$ & 516,23 & 0,000 & $7,8 \%$ & 217,29 & 0,000 \\
\hline Gender Effects & $0,0 \%$ & 0,98 & 0,401 & $0,0 \%$ & 0,41 & 0,743 & $0,0 \%$ & 1,16 & 0,322 \\
\hline RSQ dimensions ${ }^{\star 2}$ & $b$ & $t$ & $p$ & $b$ & $t$ & $p$ & $b^{\star 2}$ & $t$ & $p$ \\
\hline Importance with Independence & 0,07 & 13,40 & 0,000 & 0,04 & 5,35 & 0,000 & 0,13 & 13,53 & 0,000 \\
\hline Relationship-related Anxiety & 0,20 & 38,96 & 0,000 & 0,23 & 36,30 & 0,000 & 0,18 & 20,49 & 0,000 \\
\hline Discomfort with Closeness & 0,07 & 12,04 & 0,000 & 0,05 & 6,69 & 0,000 & 0,00 & 0,33 & 0,739 \\
\hline Importance with Independence x Born outside Sweden & $-0,09$ & $-3,93$ & 0,000 & $-0,10$ & $-3,42$ & 0,001 & & & \\
\hline Relationship-related Anxiety x Parental age & & & & 0,01 & 3,77 & 0,000 & & & \\
\hline
\end{tabular}

Spouse Relationship Problems

Social Isolation $(n=7669) \quad(n=7516) \quad$ Health Problems $(n=7722)$

\begin{tabular}{llllllllll}
\hline$\Delta R^{2}$ & $F$ & $p$ & & $\Delta R^{2}$ & $F$ & $p$ & & $\Delta R^{2}$ & $F$
\end{tabular}




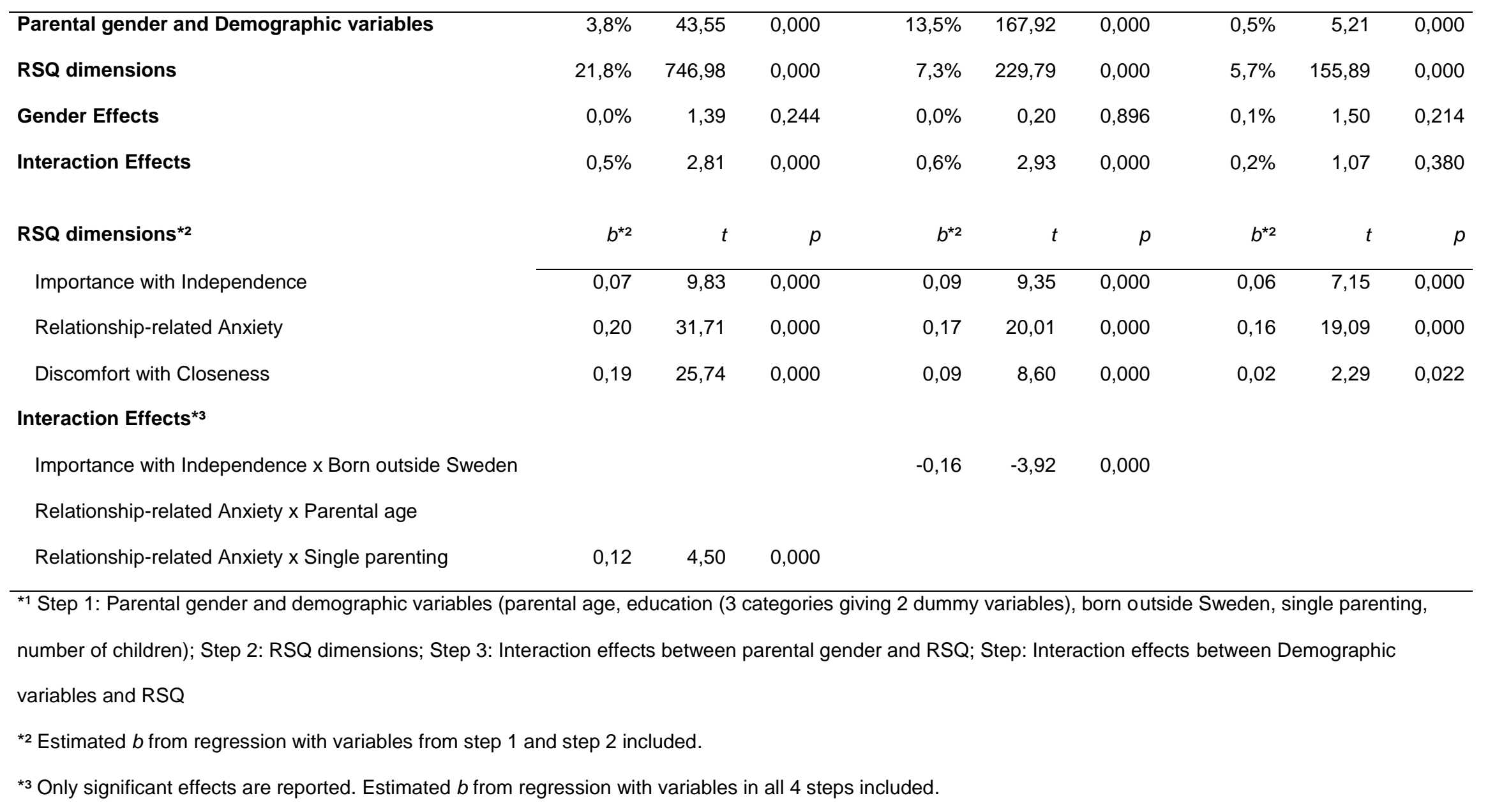




\section{Discussion}

\section{Reconstruction of RSQ}

The Relationship Style Questionnaire was translated and successfully revised into three dimensions: Importance of Independence, Relationship-related Anxiety and Discomfort with Closeness. The same dimensions were valid for mothers as well as fathers. Our three factor-solution yielded a better measure for attachment styles in a Swedish sample of parents of toddlers, than the original two factors Model of Other and Model of Self. However, the goodness of fit-values suggest that further validation is needed.

Instruments for assessing attachment style have been based on either two (Fraley, Waller, \& Brennan, 2000; Griffin \& Bartholomew, 1994a; Simpson, Rholes, \& Nelligan, 1992) or three (Collins \& Read, 1990; Collins, 1996) factors. Currently, most studies would conclude that adult attachment can be modelled by the two dimensions anxiety and avoidance (e.g. Fraley, Waller, \& Brennan, 2000; Roisman et al., 2007). When looking at the wording of the SwRSQ-14 items, we have assumed that our anxiety dimension is comparable to anxiety in other instruments and that independence and discomfort with closeness are two aspects of avoidance. This interpretation is supported by the strong correlation observed between Model of Self and Relationship-related Anxiety on the one hand, and Model of Other and the two factors Importance of Independence and Discomfort with Closeness on the other hand. This also fits with how Collins and Read understand their three dimensions; Dependence, Anxiety and Closeness (Collins \& Read, 1990; Collins, 1996) and suggests that our dimensions can be meaningfully understood and interpreted within the theory of adult attachment based on self-report. Furthermore, we would argue that the consistency of findings in two such divergent subpopulations as ours (parents of toddlers) and Collins and Read's American university students support the 
modelling of adult attachment in the three dimensions described.

The difference in results between our results and previous validations in other kinds of samples (Bäckström \& Holmes, 2001; Griffin \& Bartholomew, 1994b; Kurdek, 2002; Roisman et al., 2007; Stein et al., 2002) may depend either (1) on a true change of attachment orientation due to the transition to parenthood or (2) a change of the interpretation of the items when being a parent of a small child. There are several reasons why the interpretation might be the issue. First, in Swedish depend on can be understood both as (a) trust (Swedish: tillit) and (b) economically and/or psychologically dependent upon (Swedish: vara beroende av). The latter alternative may have a slight negative connotation due to a societal and political debate characterized by ideas of economic, social, and gender equality. In our translation of the RSQ we chose the second alternative (i.e. econ./psych. depend.), while Bäckström and Holms (2001) chose the first alternative (i.e. trust) in four of five items (the translations were carried out during the same time period, without being aware of each other's work).

Second, due to our translation, the interpretation of items concerning independence (item 1, 2, 10, 15, 22, 26) might be altered when being a parent to a toddler. This might be true in part because a child is fully dependent on his/her parents for survival and wellbeing, and because the parents might be more dependent on each other for practical and economic reasons than they had been and had been comfortable with. Hence, a temporary longing for independence may be present, resulting in higher scores on these items. Both the translation and the interpretation might be powerful reasons why avoidance was split into two distinct dimensions: independence and discomfort with closeness.

\section{Associations with parenting stress}

Complete scale of parenting stress 
We found more relationship anxiety to be associated with more overall parenting stress, which is in line with prior research suggesting an association between anxiety and stress more generally (Collins, 1996; Fraley \& Shaver 1998; Saisto et al., 2008). To our knowledge, the only two studies linking attachment styles and parenting stress have found associations between them (Rholes, Simpson, \& Friedman, 2006; Vasquez, Durik, \& Hyde, 2002). However, Vasquez et al. found fearful attachment to have the strongest association with parenting stress, Rholes et al. found avoidance to be strongest, and we found anxiety to be strongest. The seeming differences between the results can perhaps be understood by looking at the theoretical constructs model of other and model of self: Fearful attachment is seen as reflecting a negative model of other and a negative model of self, avoidant as a negative model of other and a positive model of self, and anxious as a positive model of other and negative model of self. Hence, our result combined with Rholes el al.'s result is in line with Vasquez et al.'s findings.

Rholes et al. also found a correlation between parenting stress and anxiety $(r=0.28)$ besides avoidance $(r=0.33)$. However, they conclude that particularly avoidantly attached individuals experience parenting stress after the birth of their first child (Rholes, Simpson, \& Friedman, 2006), whereas we found weak associations between parenting stress and our two avoidant dimensions. Some design differences might account for the slight differences: they assessed attachment style just before birth of the first child and parenting stress 6 months later, whereas our assessments were carried out at the same time when the target child was 2-3 years of age and on average had one sibling.

The current study showed no differences between mothers and fathers concerning the associations between attachment styles and parenting stress, which is in line with previous findings (Rholes, Simpson, \& Friedman, 2006). 


\section{Subscales of parenting stress}

Two of the five sub-scales of parenting stress - Incompetence and Social Isolation -

showed a substantially stronger (higher $R^{2}$ ) association with adult attachment. Parents who were more anxious concerning their relationships experienced a greater feeling of incompetence in their parenting as well as more social isolation as a consequence of parenting. More social isolation was also reported by parents who felt more discomfort with closeness.

Anxious attachment is often characterized by the self being seen as unlovable and unworthy (Collins \& Read, 1990; Collins, 1996; Griffin \& Bartholomew, 1994a; Ravitz et al., 2010). The association between relationship-related anxiety and perceived incompetence can perhaps be understood through the negative view of the self giving rise to a critical attitude towards one's own parenting. Our finding concerning attachment and social isolation was expected in the light of several studies: individuals classified as avoidant tend to seek less support than securely attached individuals (Collins \& Feeney, 2000; Fraley \& Shaver, 1998; Simpson, Rholes, \& Nelligan, 1992; Simpson et al., 2002), while individuals classified as preoccupied seek but cannot benefit from intimate social support (Moreira et al., 2003). Not being able to seek or benefit from close emotional support is likely to induce a feeling of social isolation. Furthermore, Östberg and Hagekull (2000) reported that social support is one of the most important predictors for parenting stress, especially for Social Isolation and hence our findings were expected. The attachment dimension regarding independence did not show any strong associations with the subscales of parenting stress, which might be a consequence of the translation and interpretation process (discussed above).

\section{Strength and limitations}


The major strengths of the present study are the large sample and the inclusion of fathers. However, as a consequence of the lack of instructions concerning which of the parents was to answer the questionnaire, our sample consists of only $3 \%$ fathers. Since the selection of fathers is unlikely to be random, it is not recommended that our findings be generalized concerning fathers to the general population. The cross-sectional design does not allow causal inferences to be made.

Further, we argue that the somewhat skewed dropout regarding demographics probably did not affect our main findings. However, a skewed dropout regarding adult attachment or parenting stress might have influenced the results and it was not possible, to analyse such a drop out. Nevertheless, we are likely to have included a heterogeneous group of parents as the sample size is large and drawn from the general population.

\section{Conclusions}

Our revision of the Relationship Scales Questionnaire in a population-based sample of parents of toddlers resulted in three dimensions of adult attachment, regardless of parental gender: Importance of Independence, Relationship-related Anxiety, and Discomfort with Closeness. The agreement with previous findings in other study populations suggests that they constitute substantial and meaningful dimensions. Attachment anxiety seems to be of importance for the perception of parenting stress, especially concerning feelings of incompetence and social isolation. Discomfort with closeness also seems to be of significance in relation to social isolation. However, we did not find any evidence that attachment-related independence is of major importance for parenting stress.

\section{References}


Abidin, R. R. (1990). Parenting Stress Index (PSI) Manual. Psychological Assessment Resources, Inc, Odessa, FL, USA.

Blunch, N. (2008) Introduction to structural equation modelling using SPSS and AMOS, Sage Publications Ltd, Thousand Oaks, CA, USA.

Bäckström, M., \& Holmes, B. M. (2001). Measuring adult attachment: A construct validation of two self-report instruments. Scandinavian Journal of Psychology, $42,79-86$.

Collins, N. L. (1996). Working Models of Attachment: Implications for Explanation, Emotion, and Behavior. Journal of Personality and Social Psychology, 71, 810832.

Collins, N. L., \& Feeney, B. C. (2000). A safe haven: An attachment theory perspective on support seeking and caregiving in intimate relationships. Journal of Personality and Social Psychology, 78, 1053-1073.

Collins, N. L., \& Read, S. J. (1990). Adult Attachment, Working Models, and Relationship Quality in Dating Couples. Journal of Personality and Social Psychology, 58, 644-663.

Essex, M. J., Klein, M. H., Cho, E., \& Kalin N. H. (2002). Maternal stress beginning in infancy may sensitize children to later stress exposure: Effects on cortisol and behavior. Biological Psychiatry, 52, 776-784.

Fraley, R. C., \& Shaver, P. R. (1998). Airport Separations: A Naturalistic Study of Adult Attachment Dynamics in Separating Couples. Journal of Personality and Social Psychology, 75, 1198-1212.

Fraley, R. C., Waller, N. G., \& Brennan, K. A. (2000). An Item Response Theory Analysis of Self-Report Measures of Adult Attachment. Journal of Personality and Social Psychology, 78, 350-365. 
Griffin, D., \& Bartholomew, K. (1994a). Models of the Self and Other: Fundamental Dimensions Underlying Measures of Adult Attachment. Journal of Personality and Social Psychology, 67, 430-445.

Griffin, D. W., \& Bartholomew, K. (1994b). The Metaphysics of Measurement: The case of Adult Attachment. Advances in Personal Relationships, 5, 17-52.

Hair, J. F., Anderson, R. E., Tatham, R. L., \& Black, W. C. (1998). Multivariate data analysis (Fifth ed.). Prentice-Hall, Upper Saddle River, NJ, USA.

Hazan, C. \& Shaver P. (1987). Romantic love conceptualized as an attachment process. Journal of Personality and Social Psychology, 52, 511-524.

Koch, F.-S., Ludvigsson, J., \& Sepa, A. (2010). Parents' Psychological Stress Over Time may Affect Children's Cortisol at Age 8. Journal of Pediatric Psychology, 35, 950-959.

Koch, F. S., Sepa, A., \& Ludvigsson, J. (2008). Psychological Stress and Obesity. The Journal of Pediatrics, 153, 839-844.

Kurdek, L. A. (2002). On being insecure about the assessment of attachment styles. Journal of Social and Personal Relationships, 19, 811-834.

McDonald, R. \& Ho, M. (2002). Principles and practice in reporting structural equation analyses. Psychological Methods, 7, 64-82.

Moreira, J. M., de Fátima Silva, M., Moleiro, C., Aguiar, P., Andrez, M., Bernardes, S., \& Afonso, H. (2003). Perceived social support as an offshoot of attachment style. Personality and Individual differences, 34, 485-501.

Ravitz, P., Maunder, R., Hunter, J., Sthankiya, B., \& Lancee, W. (2010). Adult attachment measures: A 25-year review. Journal of Psychosomatic Research, 69, 419-432.

Rholes, W. S., Simpson, J. A., \& Friedman, M. (2006). Avoidant Attachment and the Experience of Parenting. Personality and Social Psychology Bulletin, 32, 275. 
Roisman, G. I., Holland, A., Fortuna, K., Fraley, R. C., Clausell, E., \& Clarke, A. (2007). The Adult Attachment Interview and Self-Reports of Attachment Style: An Empirical Rapprochement. Journal of Personality and Social Psychology, 92, 678-697.

Saisto, T., Salmela-Aro, K., Nurmi, J.-E., \& HalmesmAki, E. (2008). Longitudinal study on the predictors of parental stress in mothers and fathers of toddlers. Journal of Psychosomatic Obstetrics \& Gynecology, 29, 219-222.

Sepa, A., Wahlberg, J., Vaarala, O., Frodi, A., \& Ludvigsson, J. (2005). Psychological Stress May Induce Diabetes-Related Autoimmunity in Infancy. Diabetes Care, $28,290-295$.

Simpson, J. A., Rholes, W. S., \& Nelligan, J. S. (1992). Support Seeking and Support Giving Within Couples in an Anxiety-Provoking Situation: The Role of Attachment Styles. Journal of Personality and Social Psychology, 62, 434-446.

Simpson, J. A., Rholes, W. S., Orina, M. M., \& Grich, J. (2002). Working Models of Attachment, Support Giving, and Support Seeking in a Stressful Situation. Personality and Social Psychology Bulletin, 28, 598.

Stein, H., Koontz, A. D., Fonagy, P., Allen, J. G., Fultz, J., Brethour, J. J. R., Allen, D., \& Evans, R. B. (2002). Adult attachment: What are the underlying dimensions? Psychology and Psychotherapy: Theory, Research and Practice, 75, 77-91.

Turner-Cobb, J. M. (2005). Psychological and stress hormone correlates in early life: A key to HPA-axis dysregulation and normalisation. Stress, 8, 47-57.

Vasquez, K., Durik, A. M., \& Hyde, J. S. (2002). Family and work: Implications of adult attachment styles. Personality and Social Psychology Bulletin, 28, 874-886. 
Östberg, M., \& Hagekull, B. (2000). A Structural Modeling Approach to the Understanding of Parenting Stress. Journal of Clinical Child Psychology, 29, 615625.

Östberg, M., Hagekull, B., \& Hagelin, E. (2007). Stability and Prediction of Parenting Stress. Infant and Child Development, 16, 207-223.

Östberg, M., Hagekull, B., \& Wettergren, S. (1997). A measure of parental stress in mothers with small children: dimensionality, stability and validity. Scandinavian Journal of Psychology, 38, 199-208. 